\title{
BMJ Open 'It has saved thousands of lives, so why change it?' Content analysis of objections to cervical screening programme changes in Australia
}

\author{
Helena M Obermair, Rachael H Dodd, Carissa Bonner, Jesse Jansen, \\ Kirsten McCaffery
}

To cite: Obermair HM, Dodd RH, Bonner C, et al. 'It has saved thousands of lives, so why change it?' Content analysis of objections to cervical screening programme changes in Australia. BMJ Open 2018;8:e019171. doi:10.1136/ bmjopen-2017-019171

- Prepublication history and additional material for this paper are available online. To view these files, please visit the journal online (http://dx.doi. org/10.1136/bmjopen-2017019171).

Received 23 August 2017 Revised 11 December 2017 Accepted 11 January 2018

Check for updates

School of Public Health, University of Sydney, Sydney, New South Wales, Australia

Correspondence to Dr Rachael H Dodd; rachael.dodd@sydney.edu.au

\section{ABSTRACT}

Objectives The incidence and mortality of cervical cancer have halved since introduction of the Australian cervical screening programme in 1991, involving 2-yearly Pap smears from ages 18-69 years. In 2017, the programme changed to 5 - yearly primary human papillomavirus (HPV) testing for women aged 25-74 years. This study investigated reasons for opposition to the renewed screening programme within the open-ended comments of an online petition, 'Stop May 1st Changes to Pap Smears-Save Women's Lives', opposing the changes, which received over 70000 signatures and almost 20000 comments.

Methods Content analysis of a random sample of 2000 comments, reflecting $10 \%$ of the 19633 comments posted in February-March 2017.

Results Nineteen codes were identified, reflecting four themes: (1) valuing women's health and rights, (2) political statements, (3) concerns about healthcare funding cuts and (4) opposition to specific components of the new screening programme. The most prevalent codes were: placing value on women's health (33\%), concerns about increasing screening intervals (17\%) and opposition to the changes related to personal experiences with cervical cancer or cervical abnormalities (15\%). Concern about the key change in technology (HPV testing instead of Pap smears) was expressed in less than $3 \%$ of comments, and some opposition to the changes from health professionals was noted.

Conclusions Screening changes within this selected group were perceived as threatening women's health, as a political policy created by male decision-makers and as a cost-cutting exercise. Many commenters were concerned about increased screening intervals and later screening onset, but little opposition was expressed regarding the testing technology itself. This analysis may inform public education and communication strategies for future changes to cervical screening programmes internationally, to pre-emptively address specific concerns about the changes.

\section{INTRODUCTION}

Cervical cancer is strongly associated with chronic cervical infection with oncogenic or 'high-risk' human papillomavirus (HPV)

\section{Strengths and limitations of this study}

- This is the first study to analyse reasons for opposition to the 2017 Australian cervical screening changes in the wider population.

- The study analysed 2000 comments (average 22 words long) from a sample of almost 20000 , providing sufficient detail to identify reasons for opposition.

- Responses to the petition by key stakeholders in this policy issue indicate the significance and size of the petition, and may have been motivated by concerns that claims in the petition were unfounded.

- We cannot determine whether the petition comments reflect the views of most Australian women; however, this petition was one of the biggest petitions on 'Change.org' in 2016-2017, indicating high public interest.

- A limitation of this study is the absence of demographic information about petitioners, so it is unknown if the sample is representative of women eligible for screening.

types. Other contributing factors include cigarette smoking and immunodeficiency. ${ }^{1}$ High-risk HPV types are a necessary, but not sufficient cause of cervical cancer. ${ }^{1-3}$ Cervical cancer is amenable to screening, with a long precancerous period. ${ }^{4}$ Until recently, screening efforts were cytology-based where cells from the cervix were manually collected by trained health professionals, smeared onto a glass slide, stained and analysed by a cytologist. ${ }^{5}$ Cytology-based screening has proven successful, halving the incidence and mortality of squamous cell cervical cancer in Australia from 1991 to 2002, where it remained steady until 2012 when it rose slightly. ${ }^{6}$

Compared with cytology-based screening, recent evidence from large international trials shows that HPV testing has increased sensitivity to detect high-grade precancerous cervical intraepithelial neoplasia or cervical 
cancer in all age groups. ${ }^{78}$ As cervical HPV infections are frequently transient and many regress, specificity of the HPV test increases with the longer screening interval. ${ }^{8}$ Furthermore, cytological abnormalities in women younger than 25 years are common and mostly transient, and population-based case-control studies show that screening young women does not result in decreased incidence of cervical cancer. ${ }^{9-11}$

Based on this evidence, and a greater knowledge of the natural history of HPV and its association with cervical cancer, screening models worldwide are currently changing from cytology to primary HPV DNA testing. In the UK, the National Screening Committee recommended primary HPV testing instead of cytology in January 2016, with an expected screening interval of 5-6 years from age 25-64. ${ }^{12-14}$ In the USA, the American Cancer Society, US Preventive Services Task Force and American College of Obstetricians and Gynecologists have recommended 3-yearly cytology from age 21-29 years, then either 3 -yearly cytology alone, or 5-yearly HPV testing, from age 30 to 65 years. ${ }^{15}$ Other countries have also decided to recommend, or have already implemented primary HPV screening, including New Zealand, Italy, Sweden and the Netherlands. ${ }^{16}$ In Australia, the National Cervical Screening Programme (NCSP) was renewed in late 2017 based on an evidence review synthesising the most up-todate research examining how these developments and greater knowledge can impact the different components of the screening programme (ie, age, screening interval, testing technology). ${ }^{17}$ Replacing the current 2-yearly cytology-based cervical screening programme from ages 18 to 69 years, both HPV-vaccinated and unvaccinated women aged 25 to 74 years will now be screened 5-yearly using primary HPV testing. ${ }^{5}$

In response to the announcement of the renewed NCSP, an online petition was created on the website 'Change. org'. ${ }^{18}$ The petition was initiated in February 2017 by an Australian woman, who stated she was motivated by 'concern and worry' after her general practitioner (GP) informed her of the changes, because '[she] didn't know about [the changes] and no one seemed to know about it'. ${ }^{19}$ The petition attracted over 70000 signatures and almost 20000 comments.

The aim of this study was to analyse the petition content of the open-ended comments to identify the themes in the objections and concerns to the renewed NCSP. This analysis could help inform public information and communication strategies for future changes to cervical screening programme internationally, by pre-emptively addressing specific concerns about the changes.

\section{METHODS}

\section{Dataset}

The dataset consists of comments posted on the "Change. org' petition 'Stop May 1st Changes to Pap SmearsSave Women's Lives' (online supplementary 1 ) between 16 February 2017 and 19 March 2017, inclusively. ${ }^{18}$ "
Change.org' is the most popular online petition website globally, with an open platform available to any member of the public who wants to initiate a petition. The 'Stop May 1st Changes to Pap Smears-Save Women's Lives' petition was one of the largest Australian online petitions in 2016 and 2017 (by number of supporters). ${ }^{20}$ The petition received exponentially fewer comments each day after the $20^{\text {th }}$ of February 2017, but still exists online to this date, receiving minimal signatures and even fewer comments each day. Comments in the dataset were on average 22 words long, ranging from one to 712 words.

\section{Procedure}

All 19633 petition comments were recorded chronologically into a Microsoft Excel spreadsheet. The spreadsheet listed the names of signatories, any original comments and dates of comment posting. A comment is defined as a piece of text published by an individual in response to a prompt on the petition, 'I am signing because...". The name and location associated with each comment were removed prior to analysis. The comments were randomised with a random number generator in Microsoft Excel and sorted into ascending order, and $10 \%$ of the dataset (2000 comments) was randomly selected for analysis.

\section{Analysis}

Content analysis combines both qualitative and quantitative methods, allowing both the frequency of categories to be reported and the content. ${ }^{21}$ Content analysis is an appropriate research method for scrutinising text data. ${ }^{22}$ It is also frequently used to analyse social media comments. ${ }^{2324}$ A large body of work has used this method to systematically categorise and quantify content in a dataset, into frames and codes. ${ }^{25-27} \mathrm{~A}$ code is a predefined category which conveys a key component of the comment.

The analysis represents the perspective of psychological health researchers and epidemiologists. HO first became familiar with the content of the comments by reading through the comments and making note of recurring themes. After an initial coding scheme was discussed with all authors and evaluated to have appropriate inter-rater reliability (ie, Kappa $>0.8$ ), it was further refined resulting in 19 categories. Two authors then applied the coding scheme to the final selection of 2000 random comments. Each comment was allocated up to six codes based on its content. HO coded all 2000 comments and RD coded $10 \%$ (200) of these comments. Cohen's Kappa was calculated using IBM SPSS Statistics V.21. Cohen's Kappa of 0.95 was achieved between the two coders, indicating 'nearly perfect' agreement. ${ }^{28}$

Descriptive statistical analysis was used to assess the frequency of each code. The codes were synthesised into four main themes through discussion with all authors once code frequency had been established. 


\section{RESULTS}

From a sample of 2000 comments, four main themes emerged from content analysis: (1) valuing women's health and rights, (2) political statements, (3) cost and healthcare funding and (4) opposition to specific components of the screening programme changes (eg, interval and age of onset of screening). The codes encompassed in each theme are outlined in table 1 with example quotes. Examples of health professional opposition were also noted.

\section{Qualitative analysis: themes arising in comments Valuing women's health and rights}

The most frequently coded statements $(32.6 \%)$ implied that the changes to the cervical screening programme would de-value and threaten women's health. This was demonstrated by comments such as, "The Pap smear program is important for women's health", "Women matter", "I want to see my daughters and grand-daughters growing up healthy" and "Women have the right to be healthy". Twenty-two per cent of commenters argued from personal experience in opposing the changes because they or somebody they knew had experienced cervical cancer or cervical abnormalities. Gender issues were discussed in $7.6 \%$ of comments, expressing opposition to men making decisions related to women's health, for example, "If men had periods and needed Pap smears, the tests would be free and be the best in the world."

\section{Political issues}

Comments expressed that the current Prime Minister and government were putting women's health at risk (13.6\%). Comments included, 'This government doesn't care about female reproductive health!", "The government is going too far this time" and, "I expected more from Malcolm Turnbull." Many comments also connected to the concept of gender, expressing the view that these changes would not be occurring if the Australian Prime Minister were a woman, if there were more female members of Parliament or if the Prime Minister had personally known someone affected by cervical cancer. Some comments included, "I think it really reflects that we need more women in decision-making", "If Malcolm [Turnbull] had a cervix these changes wouldn't be happening" and "Why does the government get to make these decisions, they are mostly men".

\section{Cost and healthcare funding}

Ten per cent of commenters believed that the changes to the cervical screening programme were a 'cost-cutting exercise', part of 'budget cuts' and that money was being 'taken' from women's health $(9.9 \%)$. Almost $6 \%$ of comments conveyed the importance of maintaining funding for healthcare in general, for example, "Lives are more important than money." Many expressed the importance of ensuring that healthcare and Pap smears should remain affordable and accessible to all women, for example, "Without government funding, some women won't be able to afford 2-yearly testing." Others argued that while these changes to cervical screening may save money in the short term, they would increase government costs in the long term, due to subsequent increased cases of cervical cancer and increased treatment costs. An example includes, "The rates in cervical cancers will undoubtedly rise and end up costing more to treat an easily screened disease" $(3.7 \%)$.

\section{Opposition to specific changes}

Change to the screening interval from 2- to 5-yearly was the most frequently expressed specific concern (16.7\%). Comments included, "Five years between tests is too long to prevent cervical cancer developing to an advanced stage." Opposition to increased age of first screening invitation was expressed in $9.1 \%$ of comments, including, "Women should be tested earlier, not later", and "25 is too old to start screening." Notably, only $2.6 \%$ of comments expressed hesitation with the HPV test itself. Comments opposing the HPV test included, "limiting the test to only screen for HPV induced cancers will put a greater number of lives at risk", and discussed that not all cervical cancers were caused by HPV, or that HPV testing is not as thorough as cytology. Just under $5 \%$ of comments expressed confidence in the current programme and argued that, "if something is not broken, don't fix it". Some commenters felt that the changes had not been communicated well, stating, "I think modifications to the testing should be thoroughly consulted across our community" and, "I don't think the explanation is very clear regarding the changes."

\section{Health professional opposition}

While not occurring frequently enough to be included in the coding scheme, some commenters expressed worry about the changes because their healthcare practitioner (GP or gynaecologist) did not support the changes. Three noteworthy comments were from people who identified themselves as GPs and one from a cytologist who commented that they had seen HPV-negative tests with an abnormal Pap smear, that 5 years was too long an interval and that they had seen cases of cervical cancer in women younger than 25 years.

\section{DISCUSSION}

This study presents comments and concerns about the 2017 changes to the Australian NCSP expressed by one of Australia's largest petitions on 'Change.org'. Many comments about women's health, politics and cost displayed significant misconceptions and misinformation about the rationale for the screening changes. Underpinning most comments in these themes was the idea that under the renewed screening programme, an increased number of cervical cancers would be missed or diagnosed at an advanced stage, and that the rationale for changes was based on reducing government healthcare costs. Many commenters voiced concerns about the increased 
Table 1 Frequency of the 19 codes in a random sample of 2000 comments made in response to the petition

Code description Example \%

Theme 1: Valuing women's health, gender and women's rights

Valuing women's health and valuing women*

"Every woman matters." "I have three daughters and I want 32.6 them to be healthy"

Personal or family/friend experience with cervical cancer/ "I have friends who had cancerous and pre-cancerous cells cervical abnormalities/other cancers on routine Pap smears BEFORE age 25." "I had an abnormal Pap smear result at 23, it could've been cancer by 24 and under these new changes I wouldn't have known until I was 25 !?"

Support for principles of disease prevention/early "Prevention is better than cure!" detection

Gender and males making decisions for/about females and women's health

"Why should a man, who will never get cervical cancer, decide my fate." "Time to let women have control, choice and safety over their own bodies!"

Right/entitlement of women to healthcare/Pap smears

"As women and taxpayers, we have a right to full

A step backwards/policy regression healthcare."

"This is a huge step backwards for women's rights."

\section{Theme 2: Political statements}

Political, encompassing:

Comments against the Prime Minister, the Liberal party; government as a whole

"The government is going too far this time." "The amount

of money the government waste on things of little to no importance and then to cut back on something as important as this just doesn't make sense."

\section{Theme 3: Cost and healthcare funding concerns}

Cost cutting

Access to health services: healthcare funding and affordability of tests

Early detection will save money in the long run

\section{"This is just another government cost-cutting exercise."}

"Healthcare should be free in the lucky country." "It is vital that Pap smears are affordable to all women."

"The government think they are saving money with this program, but they don't think of the financial burden on the health care system when there is an increase in women's cancers as a result."

\section{Theme 4: Opposition to specific components of screening programme changes}

Opposition to extended (5-yearly) screening interval Concern about missing cancer cases in young women $(<25$ years of age)

"Five years is far too long between tests."

"Young woman under the age of 20 can still get this cancer-25 is too late!"

"After 74 you don't matter?"

"I believe the conventional Pap smear screening is a great preventative program"

"Not all cervical cancers are caused by HPV."

"Pap smears should be available from when sexual activity starts as most young girls these days are having sex very young." be earlier due to earlier age of sexual activity

No specific reason stated
No reason stated for opposition
Emotional response, with no further reason for opposition
stated

*Valuing women's health was a code used in conjunction with other codes $70.2 \%$ of the time. The most frequent codes used in conjunction were (in order of frequency): disease prevention/early detection (9.5\%), cost cutting $(9.4 \%)$, politics $(8.6 \%)$, concern about screening interval (7.7\%), right/entitlement (6.0\%) and gender (5.5\%).

HPV, human papillomavirus. 
screening interval (from 2 to 5 years) and the later age of onset of screening (from 18 or 20 to 25 years of age). We noted a lack of opposition to a change from Pap smears to HPV testing itself. This may be reflective of the information and education material provided to the community in promoting the change, which focused on explaining HPV, or reflective of the lack of understanding regarding the differences between cytology and HPV testing that lead to the changes in screening interval and age. ${ }^{29}$ Another contributing factor to the significant opposition may have been news media coverage which highlighted safety concerns expressed by opposing government ministers and community members about increased screening intervals and later age of screening onset. ${ }^{19} 3031$

Previous studies conducted in Australia prior to the announcement of the changes have identified women's concerns about age of first invitation to screen, screening intervals and cost-cutting, so these issues could have been addressed in advance through better communication. ${ }^{32-34}$ A potential for cancer to be missed and a suspicion that an increased screening interval was related to cost were major concerns for women described in these publications, and are concerns shared by many commenters in our study. Internationally, publications similarly report that while HPV testing is generally accepted by women, longer screening intervals face opposition. ${ }^{35}$ It is therefore essential to educate women about the rationale for the change to screening intervals and age of first invitation to screen, namely the increased sensitivity of the HPV test and the harms of overdiagnosis and overtreatment.

Increasingly, these concerns are relayed over social media, as shown by a similar 'Change.org' petition in the UK attracting over 300000 signatures in January 2017. ${ }^{36}$ While the petition was focused on early screening options for symptomatic or high-risk groups, many comments expressed that cervical screening should be available from age 18 for all women. Concerns about increased screening intervals have also been raised by consumers in relation to other cancer types. In the USA, recommendations for later starting age of breast cancer screening and prolonged screening intervals attracted public accusations that the new proposals were politically motivated and 'anti-woman'. 3738

Opposition to the screening changes may reflect status quo bias, and general opposition of people to change. ${ }^{39}$ A significant challenge is how to present a new screening programme with major changes so that confidence in the current programme is not undermined. Patients and the public often hold the view that 'more is better' in medical care. ${ }^{40}$ This is because many patients have been socialised to fear rare, life-threatening events ${ }^{41}$ and hold fatalistic views of cancer. ${ }^{42}$ Patients also have a widespread enthusiasm for cancer screening, reflecting a lay logic that prevention and early diagnosis is universally beneficial, which is not always the case. ${ }^{43}$ The relationship between sensitivity and specificity of screening tests is a difficult concept to communicate, and public health practitioners in the past have mainly focused on sensitivity in promoting screening to the public. ${ }^{44}$ We believe much greater efforts are required by public health practitioners to better educate the public about the relative benefits and harms of screening.

There are discrepancies between benefits to the public and benefits to the individual from cancer screening. Personal experience of illness tends to be far more salient for patients than general notions of healthcare spending for society as a whole. ${ }^{45}$ Public information from government websites regarding the changes have also mentioned the harmful effects of the current Pap smear screening programme, for example, treatments for abnormal cells which can lead to increases in premature birth. ${ }^{29}$ While this approach is more effective than discussing collective waste in communicating low-value care to patients, most healthy patients still have difficulty envisioning how screening could be harmful to them. ${ }^{46}$ Our recommendations for issues to address with patients concerned about the changes are outlined in table 2.

Despite the initial announcement of the changes by the Australian government in April 2014, the changes did not garner significant publicity until 2017. The rollout of the renewed NCSP was planned for May 2017, but was delayed until December, as a component of the renewed programme, the National Cancer Screening Register, was not ready for implementation. An implementation phase was to be undertaken which included engaging with the public to assess acceptability and educating clinicians and women about the changes. ${ }^{47}$ A summary of the Medical Services Advisory Committee application for NCSP changes described limited community consultation through 2012-2013. ${ }^{48}$ Feedback was sought from, 'clinical service providers, pathology service providers, consumers, professional bodies for health professionals and pathologists, and industry', but results of these consultations are not described. While limited education has been provided to GPs through research initiatives such as the Compass trial in Victoria, ${ }^{49}$ and online education modules for clinicians were released in late $2017,^{50}$ a 2015 article in the Australian Doctor magazine reported that 'very little information has been distributed to GPs [about the changes]'. ${ }^{51}$ Ideally, clinicians would be an important group to engage and educate the public about cervical screening. The Australian Government website outlining the cervical screening changes encourages women to speak with health professionals about any concerns. ${ }^{29}$ A 2016 systematic review of 35 publications demonstrated that healthcare provider recommendation was positively correlated with improved screening rates. ${ }^{52}$

To the best of our knowledge, this is the first study to analyse reasons in the wider population for opposition to the 2017 Australian cervical screening changes since their announcement and public discussion. The study is based on 2000 randomly selected original comments from a sample of almost 20000 , and comments were on average 22 words long, providing sufficient detail to identify reasons for opposition. The importance and reach of the petition can be estimated by subsequent responses to 
Table 2 Recommended evidence for healthcare practitioners to address with patients concerned about cervical screening programme changes

\section{Concerns expressed in}

\section{online petition}

Concerns about the sensitivity of HPV testing

Concerns about 5-yearly screening interval

\section{Evidence-based responses to concerns}

HPV testing has increased sensitivity compared with Pap smear testing ${ }^{8}$ and so has the potential to detect more cervical abnormalities than cytology-based screening.

Increased sensitivity of the new HPV screening test compared with cytology to detect precancerous cervical abnormalities and cervical cancer means that screening can be less frequent while still detecting almost all cervical abnormalities. ${ }^{8}$

Risk of cervical abnormalities over 5 years is lower for an HPV-negative finding than a negative result from cytology over a 2-year or 3-year interval.

HPV testing can identify women at risk often before cell changes occur, whereas Pap smears detect changes to cervical cells after they have occurred.

Concerns about later age Most cervical abnormalities in women under the age of 25 years tend to regress by themselves, so of first invitation to screen testing early may lead to unnecessary invasive procedures. ${ }^{10}$ In women under 25 years, the harms (25, as opposed to 18 previously) are likely to outweigh the benefits of screening (eg, unnecessary invasive procedures that can cause complications) and starting screening at 25 years will reduce the number of investigations in this younger age group.

Incidence and mortality of cervical cancer in women under 25 years is very low, and this has not changed since the introduction of the screening programme.

Young women are also offered the HPV vaccination, and this is expected to lead to a significant reduction in the risk of cervical cancer in this age group.

HPV, human papillomavirus.

it from the President of the Australian Medical Association, the Australian Government Minister for Health and Australia's Chief Medical Officer. ${ }^{18}$

It could be argued that these commenters are not representative of the majority of Australian women, but simply a vocal minority. However, this petition was one of the biggest petitions on 'Change.org' in 2016 and 2017, indicating high public interest. Evidence supports the notion that public information exposure through social media has tangible impacts on health practices. ${ }^{53}$ Although the comments may not be representative of the majority of Australian women, we cannot disregard the impact that public opposition such as this can have on changes to public policy, for example, where the recommendations for changing the US breast screening programme received such a backlash that the US Preventive Services Task Force was forced to reword the recommendations. ${ }^{37} 38$ The strong views of a minority of vocal community members can be very powerful in the area of cancer screening.

Nevertheless, a limitation of this study is the absence of demographic information about petitioners, including age, gender and ethnicity. It is therefore unknown whether this sample represents women or men with lower, average or higher health literacy or educational status. If this is the case, more appropriate information targeting this demographic is required. However, it is more likely that the petition attracted responses from persons with a greater interest in health policy or women's health and may also represent a group with increased personal or family history of cervical cancer. ${ }^{37}$ It should also be noted that three commenters $(<1 \%)$ self-identified as healthcare providers opposed to the changes, which may indicate that concern is spread across socioeconomic and educational status, and that there is a need to address both professional and public concerns.

This study has practical and international implications for informing the significant challenge of rolling out future screening programme changes; in particular, changing from cytology to HPV-based cervical screening. It highlights the importance of effective communication to the public, of changes which involve longer screening intervals, later age of first invitation to screen and change in screening technology. Developing an understanding of the public's awareness of the benefits and harms of screening is crucial in the development of information about these changes. Communication must acknowledge emotions involved in this screening change, should anticipate the public's known concerns, and must engage them in the decision-making process of screening changes. Future research will explore the optimum time to involve the public in screening policy. If the public is 'misinformed and misguided', as suggested by the President of the Australian Medical Association in opposing the renewed cervical screening programme, then this could be seen as a reflection of a failure to effectively communicate the changes and their rationale. ${ }^{18} \mathrm{GPs}$, gynaecologists and other healthcare professionals who will discuss cervical screening with patients should be aware of public concern, and be prepared to discuss the reasons for the change in technology from cytology to HPV testing which result in the longer screening interval and older starting age to screening.

Contributors HMO acquired the dataset, analysed and coded 2000 comments, and drafted the manuscript. RHD was involved in the conception and design of the 
work, analysed and coded 2000 comments and drafted the manuscript. CB, JJ and $\mathrm{KM}$ were involved in the conception and design of the work, and drafting the manuscript.

Funding This research received no specific grant from any funding agency in the public, commercial or not-for-profit sectors. The research was supported by a NHMRC Program Grant (APP1113532).

Competing interests None declared.

Patient consent Not required.

Ethics approval The University of Sydney Human Research Ethics Committee reviewed and approved this study (project number 2017/300).

Provenance and peer review Not commissioned; externally peer reviewed.

Data sharing statement All data used for this manuscript are freely available online at the following website: https://www.change.org/p/malcolm-turnbull-stopmay-1st-changes-to-pap-smears-save-women-s-lives

Open Access This is an Open Access article distributed in accordance with the Creative Commons Attribution Non Commercial (CC BY-NC 4.0) license, which permits others to distribute, remix, adapt, build upon this work non-commercially, and license their derivative works on different terms, provided the original work is properly cited and the use is non-commercial. See: http://creativecommons.org/ licenses/by-nc/4.0/

(C) Article author(s) (or their employer(s) unless otherwise stated in the text of the article) 2018. All rights reserved. No commercial use is permitted unless otherwise expressly granted.

\section{REFERENCES}

1. Bosch FX, Lorincz A, Muñoz N, et al. The causal relation between human papillomavirus and cervical cancer. J Clin Pathol 2002;55:244-65.

2. Walboomers JM, Jacobs MV, Manos MM, et al. Human papillomavirus is a necessary cause of invasive cervical cancer worldwide. J Pathol 1999;189:12-19.

3. Tota JE, Chevarie-Davis M, Richardson LA, et al. Epidemiology and burden of HPV infection and related diseases: implications for prevention strategies. Prev Med 2011;53(Suppl 1):S12-S21.

4. Schiffman M, Castle PE, Jeronimo J, et al. Human papillomavirus and cervical cancer. Lancet 2007;370:890-907.

5. Australian Government Department of Health. National cervical screening program. 2017. http://www.health.gov.au/internet/ screening/publishing.nsf/Content/future-changes-cervical (cited 3 May 2017).

6. Australian Institute of Health and Welfare. Cervical screening in Australia 2013-2014. Canberra: AlHW, 2016.

7. Wright TC, Stoler MH, Behrens CM, et al. Primary cervical cancer screening with human papillomavirus: end of study results from the ATHENA study using HPV as the first-line screening test. Gynecol Oncol 2015;136:189-97.

8. Ronco G, Dillner J, Elfström KM, et al. Efficacy of HPV-based screening for prevention of invasive cervical cancer: follow-up of four European randomised controlled trials. Lancet 2014;383:524-32.

9. Vesco KK, Whitlock EP, Eder M, et al; U.S. preventive services task force evidence syntheses, formerly systematic evidence reviews. screening for cervical cancer: a systematic evidence review for the US preventive services task force. Rockville (MD): Agency for Healthcare Research and Quality (US), 2011.

10. Sasieni P, Castanon A, Cuzick J. Effectiveness of cervical screening with age: population based case-control study of prospectively recorded data. BMJ 2009;339:b2968.

11. Sigurdsson $\mathrm{K}$, Sigvaldason $\mathrm{H}$. Is it rational to start populationbased cervical cancer screening at or soon after age 20 ? Analysis of time trends in preinvasive and invasive diseases. Eur J Cancer 2007;43:769-74.

12. UK National Screening Committee (UK NSC). The UK NSC recommendation on cervical cancer screening in women. 2016. https://legacyscreening.phe.org.uk/cervicalcancer (cited 6 May 2017).

13. Royal College of Obstetricians and Gynaecologists. Progress in cervical screening in the UK. Marylebone, UK: Royal College of Obstetricians and Gynaecologists, 2016. Scientific Impact Paper No. 7.

14. NHS Cervical Screening Programme. Colposcopy and programme management. 2017. http://www.bsccp.org.uk/docs/public/pdf/ nhscsp20.pdf (cited 28 Jan 2017).
15. American College of Obstetricians and Gynecologists. Cervical cytology screening. Obstetrics and gynecology 2009;109:1409-20.

16. Dijkstra MG, van Zummeren M, Rozendaal L, et al. Safety of extending screening intervals beyond five years in cervical screening programmes with testing for high risk human papillomavirus: 14 year follow-up of population based randomised cohort in the Netherlands. BMJ 2016;355:i4924.

17. Medical Services Advisory Committee. MSAC outcomes: application no. 1276 - renewal of the National cervical screening program. In: Australian Government Medical Services Advisory Committee ed. Canberra: Australian Government, 2014:13-21

18. Rossi I. Stop May 1st changes to pap smears - save women's lives' Change.org. 2017. https://www.change.org/p/malcolm-turnbull-stopmay-1st-changes-to-pap-smears-save-women-s-lives.

19. Bowden E, Spooner R. Petition against cervical screening changes 'woefully misinformed', says AMA. Australia: The Sydney Morning Herald, 2017. (cited 6 May 2017).

20. Change.org. Most popular petitions of all time: Change.org. 2017 https://www.change.org/petitions - all-time/3 (cited 6 Jun 2017).

21. Weber RP. Content analysis. 2nd ed. Thousand Oaks, California: Sage, 1990:117-24.

22. Entman RM. Framing: toward clarification of a fractured paradigm. $J$ Commun 1993;43:51-8.

23. Hamad EO, Savundranayagam MY, Holmes JD, et al. Toward a mixed-methods research approach to content analysis in the digital age: the combined content-analysis model and its applications to health care twitter feeds. J Med Internet Res 2016;18:e60.

24. Lai LSLT WM. Content analysis of social media: a grounded theory approach. JECR 2015;16:138-52.

25. Kline KN. A decade of research on health content in the media: the focus on health challenges and sociocultural context and attendant informational and ideological problems. J Health Commun 2006;11:43-59.

26. Jenssen BP, Klein JD, Salazar LF, et al. Exposure to tobacco on the internet: content analysis of adolescents' internet use. Pediatrics 2009;124:e180-e186.

27. Sumner HM, McQueen A, Scott MJ, et al. Analysis of comments in a petition defending electronic cigarettes. Nicotine Tob Res 2014;16:1503-11.

28. Landis JR, Koch GG. The measurement of observer agreement for categorical data. Biometrics 1977;33:159-74.

29. Australian Government Department of Health. Future changes to cervical screening Australia. 2017. http://www.cancerscreening.gov. au/internet/screening/publishing.nsf/content/future-changes-cervical (cited May 7 2017).

30. McArthur G. Patients left in the dark after Federal Government secretly bungled new national cancer screening programs. Victoria, Australia: Herald Sun Newspaper, 2017. (cited 6 May 2017).

31. De Freitas C. The Government has "secretly bungled" the new cervical screening program. Australia: MamaMia, 2017. http://www. mamamia.com.au/new-cervical-screening-test-delayed/. (cited 6 May 2017).

32. Scalzo K, Mullins R. The recommended interval for cervical cancer screening: Victorian women's attitudes to an extended interval. Aust N Z J Public Health 2015;39:153-6.

33. Jayasinghe $Y$, Rangiah $C$, Gorelik A, et al. Primary HPV DNA based cervical cancer screening at 25 years: views of young Australian women aged 16-28 years. J Clin Virol 2016;76(Suppl 1):S74-S80.

34. Dieng M, Trevena L, Turner RM, et al. What Australian women want and when they want it: cervical screening testing preferences, decision-making styles and information needs. Health Expect 2013;16:177-88.

35. Ogilvie GS, Smith LW, van Niekerk DJ, et al. Women's intentions to receive cervical cancer screening with primary human papillomavirus testing. Int J Cancer 2013;133.

36. McCormick K. Make the cervical screening option available from 18 to high risk groups. 2017. Change.org. https://www.change.org/p/ the-government-lower-the-age-of-cervical-cancer-screening-to-18for-high-risk-groups (cited 10 May 2017).

37. Kiviniemi MT, Hay JL. Awareness of the 2009 US Preventive Services Task Force recommended changes in mammography screening guidelines, accuracy of awareness, sources of knowledge about recommendations, and attitudes about updated screening guidelines in women ages 40-49 and 50+. BMC Public Health 2012;12:899.

38. Davidson AS, Liao X, Magee BD. Attitudes of women in their forties toward the 2009 USPSTF mammogram guidelines: a randomized trial on the effects of media exposure. Am J Obstet Gynecol 2011;205:30. e1-30.e7.

39. Suri G, Sheppes G, Schwartz C, et al. Patient inertia and the status quo bias: when an inferior option is preferred. Psychol Sci 2013;24:1763-9. 
40. Levinson W, Kallewaard M, Bhatia RS, et al. 'Choosing Wisely': a growing international campaign. BMJ Qual Saf 2015;24:167-74.

41. Koszegi B. Health anxiety and patient behavior. J Health Econ 2003:22:1073-84

42. Vanderpool RC, Huang B. Cancer risk perceptions, beliefs, and physician avoidance in Appalachia: results from the 2008 HINTS Survey. J Health Commun 2010;15(Suppl 3):78-91.

43. Waller J, Osborne K, Wardle J. Enthusiasm for cancer screening in Great Britain: a general population survey. Br J Cancer 2015;112:562-6.

44. Esserman LJ, Thompson IM, Reid B, et al. Addressing overdiagnosis and overtreatment in cancer: a prescription for change. Lancet Oncol 2014;15:e234-e242.

45. Sommers R, Goold SD, McGlynn EA, et al. Focus groups highlight that many patients object to clinicians' focusing on costs. Health Aff 2013;32:338-46.

46. Schlesinger M, Grob R. Treating, fast and slow: Americans' understanding of and responses to low-value care. Milbank $Q$ 2017;95:70-116

47. Williams JW. Delays and confusion cloud roll-out of new cervical cancer screening program. 2017. http://theconversation.com/delaysand-confusion-cloud-roll-out-of-new-cervical-cancer-screeningprogram-73605 (cited 6 May 2017).
48. Australian Government Medical Services Advisory Committee. Application No. 1276 - Renewal of the National Cervical screening program. In: Committee MSA ed. Canberra: Australian Government, 2014:2-3.

49. Canfell K, Caruana M, Gebski V, et al. Cervical screening with primary HPV testing or cytology in a population of women in which those aged 33 years or younger had previously been offered HPV vaccination: results of the Compass pilot randomised trial. PLoS Med 2017; 14:e1002388.

50. Australian Government Department of Health. National cervical screening program. Australia: NPS MedicineWise: Australian Government Department of Health, 2017. (cited 29 Sep 2017).

51. Klein A, Woodhead M. Switch from Pap smears delayed until 2017. Australia: Australian Doctor, 2015. (cited 6 May 2017).

52. Peterson EB, Ostroff JS, DuHamel KN, et al. Impact of providerpatient communication on cancer screening adherence: A systematic review. Prev Med 2016;93:96-105.

53. Dunn AG, Surian D, Leask J, et al. Mapping information exposure on social media to explain differences in HPV vaccine coverage in the United States. Vaccine 2017;35:3033-40. 